\title{
(2) OPEN ACCESS \\ Injury rates decreased in men's professional football: an 18-year prospective cohort study of almost 12000 injuries sustained during 1.8 million hours of play
}



- Additional material is published online only. To view please visit the journal online (http://dx.doi.org/10.1136/ bjsports-2020-103159).

${ }^{1}$ Health, Medicine and Caring Sciences, Linköping University, Linköping, Sweden

${ }^{2}$ Football Research Group, Linköping University, Linköping, Sweden

${ }^{3}$ Center for Health Services Development, Linköping University, Linköping, Sweden ${ }^{4}$ Department of Sports Medicine, Oslo Sports Trauma Research Center, Norwegian School of Sports Sciences, Oslo, Norway ${ }^{5}$ Department of Research, Aspetar Orthopaedic and Sports Medicine Hospital, Doha, Qatar

Correspondence to Professor Jan Ekstrand, Health, Medicine and Caring Sciences, Linköping University, Linköping S-582 20, Sweden; jan.ekstrand@telia.com

Accepted 23 January 202
Check for updates

(C) Author(s) (or their employer(s)) 2021. Re-use permitted under CC BY-NC. No commercial re-use. See rights and permissions. Published by BMJ.

To cite: Ekstrand J, Spreco A, Bengtsson $\mathrm{H}$, et al. Br J Sports Med Epub ahead of print: [please include Day Month Year]. doi:10.1136/ bjsports-2020-103159

\section{ABSTRACT}

Background The UEFA Elite Club Injury Study is the largest and longest running injury surveillance programme in football.

Objective To analyse the 18-season time trends in injury rates among male professional football players. Methods 3302 players comprising 49 teams (19 countries) were followed from 2000-2001 through 2018-2019. Team medical staff recorded individual player exposure and time-loss injuries.

Results A total of 11820 time-loss injuries were recorded during 1784281 hours of exposure. Injury incidence fell gradually during the 18-year study period, $3 \%$ per season for both training injuries $(95 \% \mathrm{Cl} 1 \%$ to $4 \%$ decrease, $p=0.002)$ and match injuries $(95 \% \mathrm{Cl} 2 \%$ to $3 \%$ decrease, $p<0.001)$. Ligament injury incidence decreased $5 \%$ per season during training $(95 \% \mathrm{Cl} 3 \%$ to $7 \%$ decrease, $p<0.001)$ and $4 \%$ per season during match play (95\% Cl $3 \%$ to $6 \%$ decrease, $p<0.001)$, while the rate of muscle injuries remained constant. The incidence of reinjuries decreased by $5 \%$ per season during both training $(95 \% \mathrm{Cl} 2 \%$ to $8 \%$ decrease, $\mathrm{p}=0.001)$ and matches ( $95 \% \mathrm{Cl} 3 \%$ to $7 \%$ decrease, $\mathrm{p}<0.001)$. Squad availability increased by $0.7 \%$ per season for training sessions ( $95 \% \mathrm{Cl} 0.5 \%$ to $0.8 \%$ increase, $\mathrm{p}<0.001)$ and $0.2 \%$ per season for matches $(95 \% \mathrm{Cl} 0.1 \%$ to $0.3 \%$ increase, $p=0.001$ ).

Conclusions Over 18 years: (1) injury incidence decreased in training and matches, (2) reinjury rates decreased, and (3) player availability for training and match play increased.

\section{INTRODUCTION}

The ultimate goal for professional football clubs is to win games, titles and trophies. ${ }^{1}$

For team success, avoiding injuries may be essential; a low number of injuries allow coaches to have the most complete squad (usually around 25 players from which to pick the 11-member team) available for training and matches. In fact, $\mathrm{we}^{2}$ and others ${ }^{34}$ have previously shown that injuries affect performance negatively and that lower injury rates are linked to success in national and international matches. Hence, avoiding injuries is of utmost importance. ${ }^{5}$

In 1999, the UEFA initiated a research project aimed at following injury rates and injury patterns over time, reducing the number and severity of injuries and increasing player safety. ${ }^{6-8}$ Conducting injury surveillance is the fundamental first step in the sequence of prevention ${ }^{5}$ and thus an injury surveillance study was launched in 2001. This study, the Elite Club Injury Study (ECIS), has so far involved 69 European top-level teams from 20 different European countries over 18 seasons.

Football has changed a great deal since ECIS was launched; there are more games per calendar year and objective data show that the players run farther than they used to, with more frequent high-speed efforts. ${ }^{9}$ An advantage of a long-term study, such as ECIS, is that it can reveal trends. ${ }^{10-14}$ Previously published 7 and 11-year follow-ups of ECIS did, however, not identify any significant changes in training or match injury incidence over time. ${ }^{67}$

The purpose of the present study was to analyse whether there have been any time trends in injury rates during 18 seasons from 2001/2002 through 2018/2019. Our hypothesis was that injury incidence and injury burden had been stable over time.

\section{METHODS}

ECIS is a prospective cohort study initiated and funded by the European football association, UEFA. ECIS was launched in July 2001 and has since then been conducted over 18 consecutive seasons. Before the start of a new European football season, all teams that qualified for the UEFA Champions League (UCL) group stage were invited to participate in ECIS during the upcoming season. Teams that had participated in ECIS during the previous season were also invited to continue their participation, even if they did not qualify for the subsequent UCL group stage. All players from the first team squads of participating clubs were asked to give their written informed consent to be included in the study.

\section{Patient involvement}

This research was done without patient (football player) involvement. Patients were not invited to comment on the study design or to contribute to the writing or editing of this document.

\section{Study procedure}

Teams that agreed to participate in ECIS were asked to assign a contact person (a member of the medical staff) who was responsible for registering the necessary data during the season. All contact persons were given a study manual, including a detailed description of the study methodology, to ensure they understood the data registration process and were familiar with all operational definitions used in the study (table 1). Teams were asked to provide the study group with data each month. All registered data were reviewed by members of the study group to ensure that it complied with the study protocol. If any missing or unclear data 


\begin{tabular}{|c|c|}
\hline Training session & $\begin{array}{l}\text { Team training that involved physical activity under the } \\
\text { supervision of the coaching staff }\end{array}$ \\
\hline Match & Competitive or friendly match against another team. \\
\hline Injury & $\begin{array}{l}\text { Any physical complaint sustained by a player that resulted } \\
\text { from a football match or football training and led to the } \\
\text { player being unable to take full part in future football training } \\
\text { or match play. }\end{array}$ \\
\hline Ligament injury & Traumatic distraction injury to a ligament. \\
\hline Muscle injury & Traumatic distraction or overuse injury to a muscle. \\
\hline Injury incidence & $\begin{array}{l}\text { Number of injuries per } 1000 \text { player hours }((\Sigma \text { injuries } / \Sigma \\
\text { exposure hours }) \times 1000) \text {. }\end{array}$ \\
\hline Injury burden & $\begin{array}{l}\text { Number of lay-off days per } 1000 \text { player hours ( } \Sigma \text { lay-off } \\
\text { days } / \Sigma \text { exposure hours }) \times 1000) \text {. }\end{array}$ \\
\hline Squad availability & $\begin{array}{l}\text { The average percentage of players available for training and } \\
\text { match selection (eg, not absent due to injury, illness, national } \\
\text { team duty or other reasons). }\end{array}$ \\
\hline Injury absence & $\begin{array}{l}\text { The average percentage of players who were absent from } \\
\text { trainings and match selection due to injury. }\end{array}$ \\
\hline Reinjury & $\begin{array}{l}\text { Injury of the same type and at the same site as an index } \\
\text { injury. }\end{array}$ \\
\hline
\end{tabular}

were identified during this review process, immediate feedback was sent to the contact person to complete or correct the data. Data for the current study were collected between July 2001 and May 2019. The study methods followed international consensus statements closely and a detailed description of the methods has been published previously. ${ }^{1516}$

The methodology was also consistent with recommendations from an IOC consensus statement from 2020, even though data registration was completed before this statement was published. ${ }^{17}$

\section{Study population}

To increase homogeneity in this substudy, we only included teams during seasons that they participated in the UCL group stage in the analyses. This selection was made since the number of teams that failed to qualify for the UCL group stage has increased during the course of the study and since there could be some important differences between teams that qualified for the UCL group stage and teams that did not (eg, match schedules, financial conditions, and so on). During 18 seasons, a total of 49 participating teams from 19 European countries participated in the UCL group stage and were included in the present study.

\section{Inclusion and exclusion criteria}

All players with a first team contract were invited to participate in the study on a voluntary basis, adding up to a total of 3302 included players. Players who left or joined the team during the season (eg, due to transfer) were included during their time on the team.

\section{Exposure}

Individual football exposure was registered on an attendance record. The attendance record included information about the duration in minutes for each exposure (including training and match play), as well as whether players were absent due to injury, illness, national team duty or for other reasons.

\section{Injury}

An injury was defined using a time-loss definition (table 1). For each injury that occurred, the contact person was asked to complete an injury card. The injury card included information about the injury diagnosis, injury occasion and the mechanisms causing the injury. Based on the information on the injury card, members of the study group classified the injury using the Orchard Sports Injury Classification System. ${ }^{18}$ Injuries that did not occur during a specific identifiable event (eg, overuse injuries) were assigned to the last activity (training or match) that the injured player was able to complete before being removed from full participation in team activities. Reinjury was defined as an 'injury of the same type and at the same site as an index injury' irrespective of injury occasion, injury mechanism and the time between the injury and a potential index injury.

Players were considered injured until the medical team cleared the player for full participation in all team activities, including both training and match play. Lay-off following an injury was defined as the number of days from the date of injury until the date when the medical team declared the player as ready for full participation.

\section{Data analyses}

Continuous data are presented as means with SDs. Four injury measures were analysed for all injuries, ligament injuries and muscles injuries: (1) injury incidence in training, (2) injury incidence in matches, (3) injury burden for training injuries, and (4) injury burden for match injuries. Injury incidence was expressed as the number of injuries per 1000 hours of exposure. Injury burden was expressed as the sum of lay-off days caused by an injury category per 1000 hours of exposure. Specific analyses of muscle and ligament injuries were performed since these are the two most common injury types in professional football. ${ }^{7}$ Squad availability was expressed as the average percentage of players available for training and match selection (eg, not absent due to injury, illness, national team duty or other reasons). Injury absence was expressed as the average percentage of players who were absent from trainings or unavailable for match selection due to injury.

For injury incidence and reinjury incidence, respectively, timetrend analysis was performed using Poisson regression with log link function and overdispersion with number of injuries as dependent variable, season as independent variable and logtransformed exposure as offset variable. Corresponding analysis was performed for injury burden with the number of days absence as the dependent variable. Injury absence was modelled as binomial distribution (log link) with overdispersion where the number of missed trainings/matches was considered the number of 'successes', the number of played trainings/matches was considered the number of 'failures' and season was used as independent variable. For the remaining injury rate variables, time-trend analysis was performed using linear regression with the log-transformed injury rate as dependent variable and season as independent variable. The regression equations were used to also estimate annual change in expected rate, expressed as per cent, by using the formula $100^{*}(\exp (\mathrm{b} 1)-1)$, where $\mathrm{b} 1$ is the slope in the linear expression. Analyses were two sided and the significance level was set at $\mathrm{p}<0.05$.

\section{RESULTS}

A total of 265 'team seasons' from 49 teams were included in the analyses. During these seasons, a total of 11820 injuries were reported during 1784281 hours of exposure, representing a total injury incidence of $6.6 / 1000$ hours (95\% CI 6.5 to 6.7). The majority of the reported injuries occurred during match play (6785 match injuries and 5035 training injuries), representing a match injury incidence of 23.8/1000 hours. The injury 
Table 2 Descriptive data of injuries and availability during 18 seasons of the UEFA Elite Club Injury Study

\begin{tabular}{|c|c|c|}
\hline & During training & During matches \\
\hline \multicolumn{3}{|l|}{ Injury incidence } \\
\hline Injury incidence, injuries per 1000 hours of exposure $(95 \% \mathrm{Cl})$ & 3.4 (3.3 to 3.5$)$ & $23.8(23.2$ to 24.4$)$ \\
\hline Ligament injury incidence, injuries per 1000 hours of exposure $(95 \% \mathrm{Cl})$ & $0.5(0.4$ to 0.5$)$ & $4.4(4.2$ to 4.7$)$ \\
\hline Muscle injury incidence, injuries per 1000 hours of exposure $(95 \% \mathrm{Cl})$ & $1.3(1.3$ to 1.4$)$ & $9.7(9.3$ to 10.0$)$ \\
\hline \multicolumn{3}{|l|}{ Injury severity } \\
\hline Injury severity, average days absence (SD) & $18(31)$ & $21(34)$ \\
\hline Ligament injury severity, average days absence (SD) & $23(42)$ & $32(52)$ \\
\hline Muscle injury severity, average days absence (SD) & $15(17)$ & $18(20)$ \\
\hline \multicolumn{3}{|l|}{ Injury burden } \\
\hline Injury burden, days absence per 1000 hours of exposure & $60.5(56.5-64.5)$ & $504.6(475.6-533.6)$ \\
\hline Ligament injury burden, days absence per 1000 hours of exposure & $10.9(9.2-12.6)$ & $141.0(125.2-156.8)$ \\
\hline Muscle injury burden, days absence per 1000 hours of exposure & $20.0(18.4-21.6)$ & $178.4(164.7-192.1)$ \\
\hline \multicolumn{3}{|l|}{ Reinjuries } \\
\hline Overall reinjury incidence, injuries per 1000 hours of exposure $(95 \% \mathrm{Cl})$ & $0.4(0.4$ to 0.4$)$ & $2.2(2.0$ to 2.3$)$ \\
\hline Ligament injury reinjury incidence, injuries per 1000 hours of exposure $(95 \% \mathrm{Cl})$ & $0.1(0.0$ to 0.1$)$ & $0.3(0.3$ to 0.4$)$ \\
\hline Muscle injury reinjury incidence, injuries per 1000 hours of exposure $(95 \% \mathrm{Cl})$ & 0.1 (0.1 to 0.2$)$ & $1.0(0.9$ to 1.2$)$ \\
\hline \multicolumn{3}{|l|}{ Injury absence } \\
\hline Injury absence* (SD) & $11.2(4.3)$ & $11.3(4.4)$ \\
\hline
\end{tabular}

${ }^{*}$ Injury absence was expressed as the average percentage of players who were absent from trainings or unavailable for match selection due to injury.

incidence in training was 3.4/1000 hours (table 2). Muscle injuries $(n=4763)$ and ligament injuries $(n=1971)$ comprised $57 \%$ of all injuries reported.

\section{Team statistics}

The average squad size was 25 (95\% CI 22 to 28 ) players. Teams had on average 215 (95\% CI 177 to 253) training sessions and played 60 (95\% CI 52 to 68) first team matches per season, corresponding to an average of 3.6 (95\% CI 3.0 to 4.2$)$ training sessions for each match played.

Time trends for injury incidence

Time-trend analyses showed decreases in injury incidence, 3\% per season during the 18-year study period, in both training and matches. Ligament injury incidence also decreased over the study period, with $5 \%$ per season in training and $4 \%$ per season

Table 3 Results from the analyses showing the seasonal percentages of change in injury incidence, injury severity, injury burden, reinjury incidence, injury absence and match availability/training attendance between the 2001/2002 and the 2018/2019 season. Results are expressed as the seasonal change, with $95 \% \mathrm{Cls}^{*}$

\begin{tabular}{|c|c|c|c|c|c|c|}
\hline & \multicolumn{3}{|l|}{ During training } & \multicolumn{3}{|l|}{ During matches } \\
\hline & Seasonal change (\%) & $95 \% \mathrm{Cl}$ & $P$ value & Seasonal change (\%) & $95 \% \mathrm{Cl}$ & $P$ value \\
\hline \multicolumn{7}{|l|}{ Injury incidence } \\
\hline Ligament injury incidence & -5 & -7 to -3 & $<0.001$ & -4 & -6 to -3 & $<0.001$ \\
\hline Muscle injury incidence & -1 & -2 to 1 & 0.498 & -1 & -2 to 1 & 0.268 \\
\hline \multicolumn{7}{|l|}{ Injury severity } \\
\hline Muscle injury severity & 1 & -1 to 3 & 0.294 & 1 & 0 to 3 & 0.051 \\
\hline \multicolumn{7}{|l|}{ Injury burden } \\
\hline Injury burden & -2 & -4 to 0 & 0.083 & -2 & -2 to -1 & 0.001 \\
\hline Ligament injury burden & -1 & -5 to 4 & 0.759 & -2 & -5 to 0 & 0.095 \\
\hline Muscle injury burden & 0 & -2 to 2 & 0.773 & 1 & -1 to 2 & 0.936 \\
\hline Muscle reinjury incidence & -3 & -7 to 0 & 0.059 & -4 & -7 to -2 & 0.002 \\
\hline \multicolumn{7}{|l|}{ Availability/injury absence } \\
\hline Availability & 0.70 & 0.5 to 0.8 & $<0.001$ & 0.20 & 0.1 to 0.3 & 0.001 \\
\hline Injury absence & -2 & -3 to -1 & $<0.001$ & -2 & -3 to -1 & $<0.001$ \\
\hline
\end{tabular}

Negative values represent a reduction. Positive values represent an increase.

*The dependent variables injury severity and availability were log transformed. Tests for normality (Kolmogorov-Smirnov and Shapiro-Wilk) showed that this transformation was appropriate for the dependent variables. 
in match play. There was no change in muscle injury incidence over time (table 3 , figures 1 and 2 ).

\section{Time trends for injury severity}

There were no significant trends in the severity (average number of days lost) of all injuries or muscle injuries in training. However, the severity of ligament injuries in training increased $4 \%$ per season. The severity of match injuries also increased, $1 \%$ per season, while no significant trends were observed for ligament or muscle injuries that occurred in matches (table 3, figures 1 and 2).

\section{Time trends for injury burden}

The overall burden of match injuries fell by $2 \%$ per season while no statistically significant change in burden of training injuries was observed. In addition, no significant trends were detected for the burden of ligament or muscle injury, neither in training nor in matches (table 3, figure 3).

\section{Time trends for reinjury incidence}

The reinjury incidence decreased 5\% per season both during training and match play. There were similar trends for ligament reinjuries, with a $6 \%$ decrease in training and $7 \%$ decrease in matches. Muscle reinjury incidence decreased $4 \%$ in matches, but there was no significant decrease in training (table 3 , figures 1 and 2).

Time trends for injury absence and squad availability Squad availability for both training sessions and matches increased over the study period with $0.7 \%$ per season for training sessions and $0.2 \%$ per season for matches. Converse changes were observed for the average squad absence due to injury (table 3 , figure 3 ).

\section{DISCUSSION}

This unique ECIS data set allows us to explore 18-year trends for key football injury epidemiological data. Since we have previously reported 7 and 11 -year data ${ }^{67}$ from the ECIS, we provide these, for the reader's convenience, alongside the 18-year data in table 4. In comparison to the 7-year follow-up, the 18-year data indicate a $13 \%$ and $17 \%$ lower match and training injury incidence, respectively.

The data from table 3, taken together with the 18-year longitudinal data plots in the Results section, allow us to draw six major conclusions:

- The overall injury rate has decreased in training and matches.

- The ligament injury rate has decreased in training and matches.

- The muscle injury rate has not decreased, neither in training nor in matches.

- The burden of injury has remained stable.

- The reinjury rate has decreased.

- Player absence from training and matches has decreased.

\section{Can we explain why injury rates changed?}

This is a prospective epidemiological study revealing significant associations. Causative factors cannot be evaluated using this study design; we do not know the reasons for the observations. However, after 18 years of monthly contacts with these elite-level teams, we do have some hypotheses. We also organise an annual meeting with all the chief medical officers of the clubs participating in the ECIS for discussions on how to reduce injuries, keep the players available and increase performance of the teams. At such a meeting in Porto 2013, we asked for the chief medical officers' views on the most important risk factors contributing to injuries. The four most common factors listed were: (1) the leadership style of the head coach, (2), the quality of internal communication, (3) the workload imposed on players, and (4) player well-being. ${ }^{19-22}$

This suggests that preventive strategies targeting player-related risk factors may not, on their own, be sufficient to significantly reduce injury rates at elite level. ${ }^{10}$ Accordingly, alternative risk factors need to be investigated to determine whether there is a correlation with injury rates and to provide guidance to the most appropriate preventive measures to be adopted. ${ }^{8}$ We have studied some of these and found associations between injury rates and the leadership style of the head $\operatorname{coach}^{21}$ as well as the quality of the internal communication within a team. ${ }^{22}$ While speculative, it is plausible that a better understanding of how these kinds of 'alternative' risk factors may be associated with injuries has contributed to the decreasing injury rates that were observed in the present study.

\section{What does this mean, practically?}

The decrease in injury incidence by $3 \%$ per season in training and $3 \%$ per season in matches observed in the present study is encouraging - a success story in the world of football medicine. Further, the reinjury rate, $10 \%$ of all injuries, is low in this male elite club cohort and it decreased by 3\%-7\% during the 18 -year period. The lower reinjury rate is maybe the most important finding in the study.

In comparison to when the ECIS was launched, we now have better diagnostic abilities (multiple-angle video analysis of mechanisms, better correlated clinical tests, higher resolution MRI scanners, new grading methods) and improved appreciation of which injures need longer or more comprehensive rehabilitation in order to prevent reinjury (eg, syndesmosis injuries, ACL rehabilitation times, central tendon involvement of muscle injuries). This improved diagnostic ability and injury appreciation may also explain the trend towards increased severity as rehabilitation times are extended for certain injuries. This goes hand in hand with a more criteria-based return to play philosophy as we better understand physical quality measures associated with injury and reinjury (eg, strength markers, eccentric hamstring strength).

Absence from training and matches has also decreased. Injury absence and total squad availability (which to a large extent is decided by the number of players absent due to injury) are the most important variables to communicate to non-medical stakeholders, since low injury absence has been linked with better team performance. ${ }^{2-4}$ It is therefore encouraging to see that absence due to injury has decreased over the study period.

\section{How can our findings be of practical value for players,} clinicians and clubs?

According to statements at recent postseason meetings, many of the ECIS teams have improved their communication and strategies to prevent injuries and, because of this, improved their results. Team medical staff has created awareness of preventing injuries, underlining the necessity to communicate and cooperate with coaching, performance and administrative staff. These efforts need to be expanded, in collaboration between medical staff, coaches and directors, to analyse how the game evolves, and to find solutions to keep the players safe and at less risk.

Most current team physicians can be considered as specialised football doctors based on their experience, commitment 

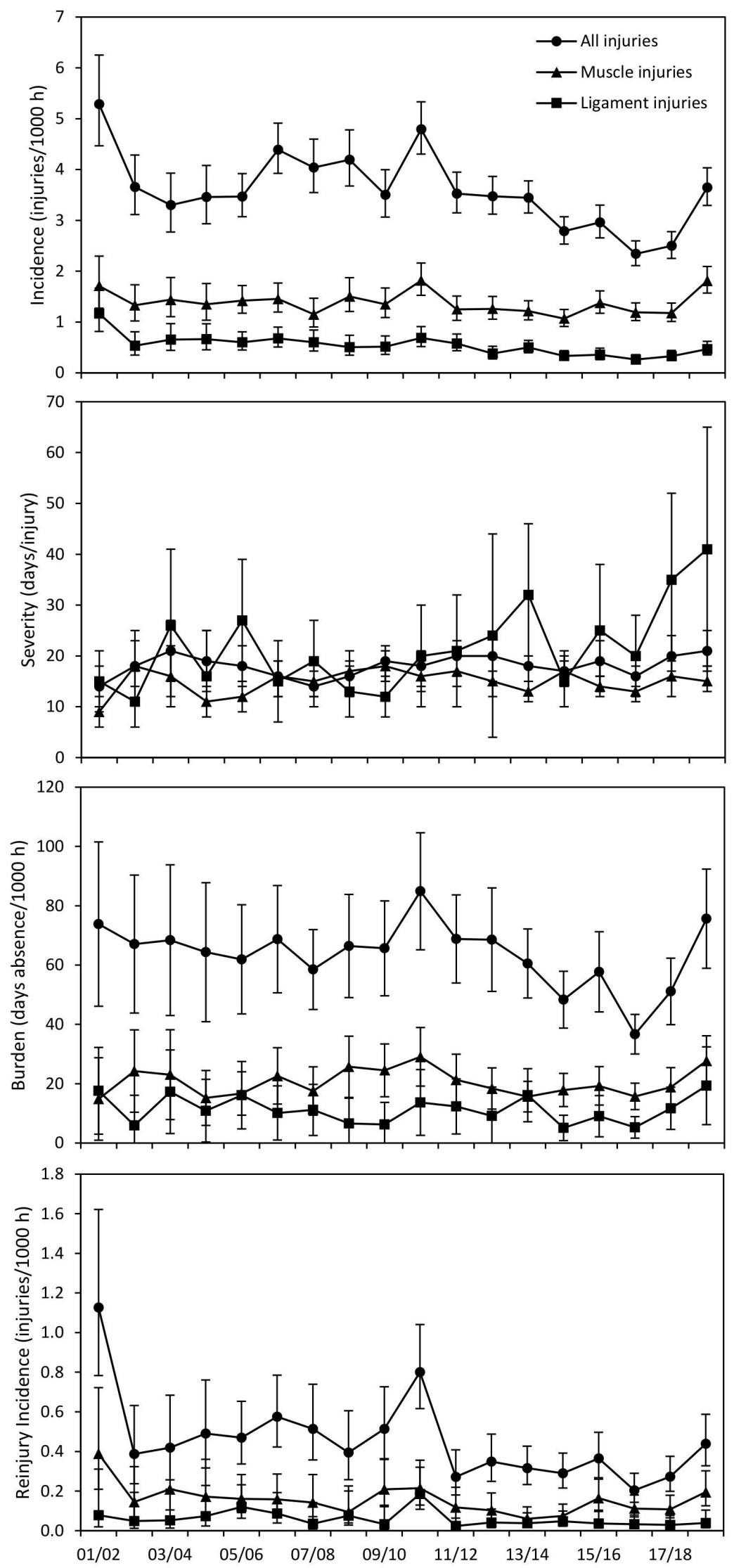

Figure 1 Training injuries. Time course of injury incidence, injury severity, injury burden and reinjury rate for all injuries, muscle injuries and ligament injuries over the study period. Injury incidence is defined as the number of injuries per 1000 hours of training exposure with $95 \% \mathrm{Cl}$. Injury severity is defined as the average number of absence days following training injuries with $95 \% \mathrm{Cl}$. Injury burden is defined as the number of absence days caused per 1000 hours of training exposure with $95 \% \mathrm{Cl}$. Reinjury rate is defined as the number of reinjuries per 1000 hours of training exposure with $95 \% \mathrm{Cl}$. 

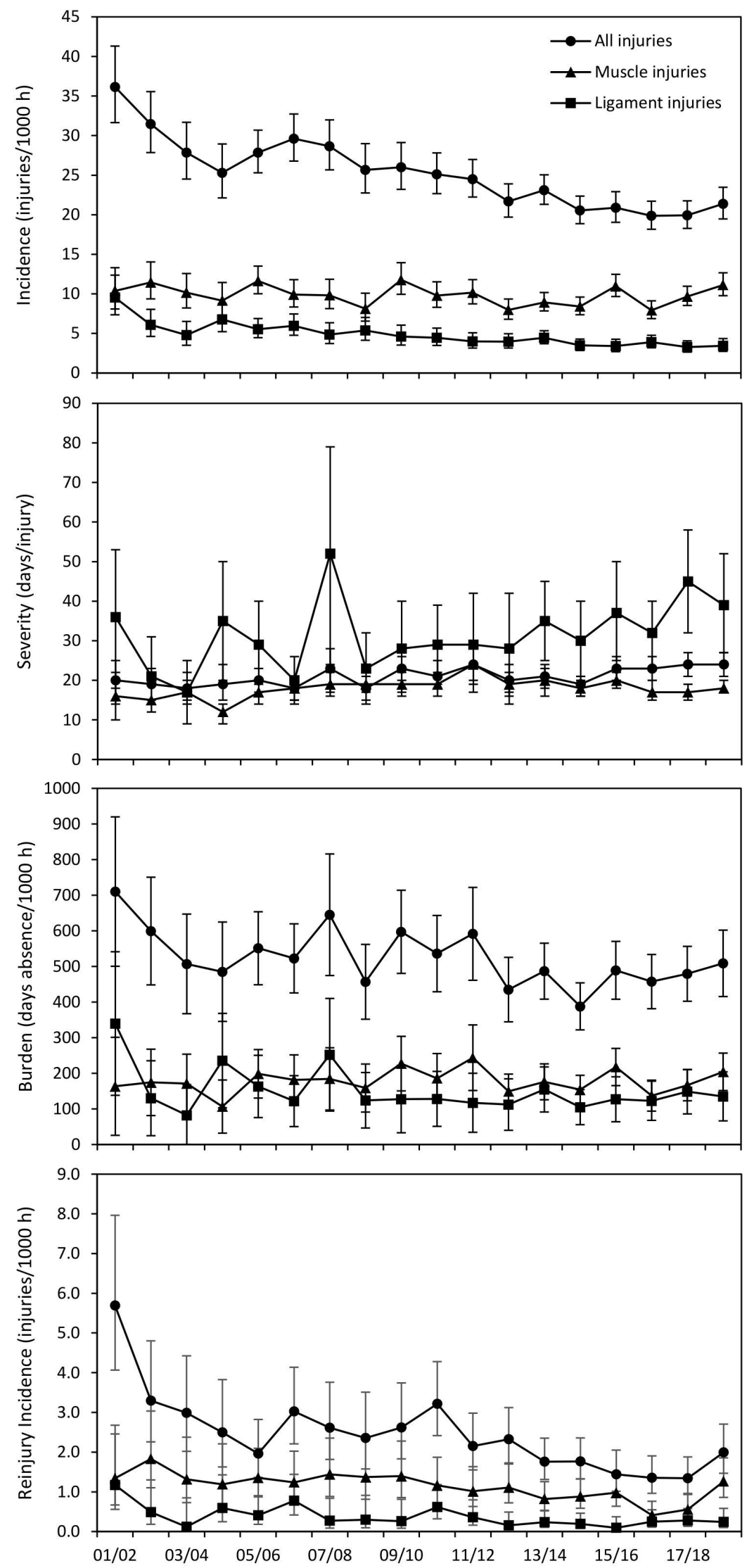

Figure 2 Match injuries. Development of injury incidence, injury severity, injury burden and reinjury rate for all injuries, muscle injuries and ligament injuries in matches over the study period. Injury incidence is defined as the number of injuries per 1000 hours of match exposure with $95 \% \mathrm{Cl}$. Injury severity is defined as the average number of absence days following match injuries with $95 \% \mathrm{Cl}$. Injury burden is defined as the number of absence days caused per 1000 hours of match exposure with $95 \% \mathrm{Cl}$. Reinjury rate is defined as the number of reinjuries per 1000 hours of training exposure with $95 \% \mathrm{Cl}$. 

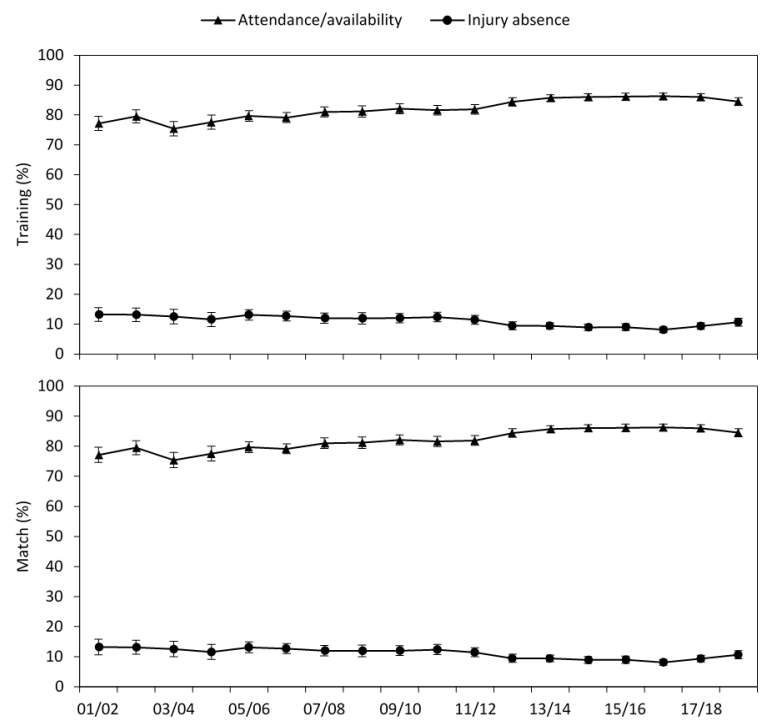

Figure 3 Development of player availability and injury absence in training and in matches over the study period. Player availability is defined as the average proportion of training sessions and matches when players were available to participate with $95 \% \mathrm{Cl}$. Injury absence is defined as the average proportion of training sessions and matches when players were unavailable to participate due to injury with $95 \% \mathrm{Cl}$.

to football medicine and investment in skills and knowledge. Medical staff has advanced, and the requirements to coach at the highest professional football level have increased. It is plausible to state that the head coaches of 2020 are better educated and prepared for their job than their colleagues from the start of ECIS in 2001. We have shown that the leadership style of the coach may impact injury variables and better educated coaches may thus have influenced the injury numbers positively.

However, we have to ask what the medical team member can influence and change? Probably not the leadership of the head coach and probably not the load on the players, but definitely the internal communication among doctors, physiotherapists and coaches, and the well-being of the players. The medical team could focus on these issues.

We must also continue to embrace all strategies that are useful to prevent injuries, for example, neuromuscular training. Even at the elite level, implementation of preventive exercises and player compliance to these exercises can be further improved, even though the standard is already high in many clubs. ${ }^{23}$ In professional football, the main focus of training sessions is to improve the footballing ability of players. To increase coaches and players' buy-in to preventive exercises it may be important that those exercises also contribute to the main focus of the training sessions. ${ }^{23}$ Difficulties in implementing preventive exercises and

Table 4 Injury statistics from the present study and two previously published follow-ups of the UEFA Elite Club Injury Study data set

\begin{tabular}{|c|c|c|c|}
\hline & 7-year data ${ }^{6}$ & 11-year data ${ }^{7}$ & 18-year data \\
\hline Exposure hours & 566000 & 1060000 & 1780000 \\
\hline Injuries & 4483 & 8029 & 11820 \\
\hline Injury incidence* & 8.0 & 7.6 & 6.6 \\
\hline Match injury incidence* & 27.5 & 26.7 & 23.8 \\
\hline Training injury incidence* & 4.1 & 4.0 & 3.4 \\
\hline Reinjury proportion (\%) & 12 & 12 & 10 \\
\hline
\end{tabular}

*Injuries per 1000 hours of exposure. keep players compliant may be a reason why muscle injuries have not decreased over the past 18 years.

\section{Injury prevention may be working}

Let us contextualise the observed time trends of different injury variables that we present in this study. Since 2001, when ECIS was launched, the intensity of football matches has increased with an increasing number of high-intensity activities per match and higher maximum running speed of professional players. ${ }^{9}$ Injuries are more likely to occur during high-intensity activities, such as running and sprinting, ${ }^{24}$ and it is reasonable to expect that such changes (more high-speed activities) would increase risk of injury.

In addition, there are now more games per season than previously and an increasing rate of matches increases risk of injury. ${ }^{25}$ Why has injury incidence decreased as professional footballers have been exposed to at least some factors that increase injury risk? The advocates for sports injury prevention appreciate that injuries occur due to a complex and multivariate system, with multiple risk factors and risk factor interactions, ${ }^{26}$ and that this complexity needs to be considered to effectively prevent injuries. We would argue that, over this 18 -year period, injury prevention has become increasingly effective and football doctors and physiotherapists have become more efficient in identifying, intervening and contributing to a reduced number of injuries despite increasing demands.

\section{Methodological considerations}

A main strength of this study is that the prospective study design follows international consensus on epidemiological research in sport closely and allows for comparisons with other studies following similar methodologies. ${ }^{15-17}$

Also, several steps were taken to increase the reliability of the collected data, such as a detailed study manual and close communication between the study group and all participating teams, and so on. ${ }^{17}$ Even though a prospective cohort study as the present is considered the gold standard in terms of epidemiological research, the quality of the reported data is of utmost importance. A continuous and close contact between researchers and informants is the best way to increase quality of reported data which is the main reason why we insist that teams deliver data monthly. As we review all data that are reported to us, we make sure that it is in accordance with the study methodology. In addition, we meet with the informants every year to inform them on the progress of the study and emphasise the importance of high data quality.

Further, the study period spanned 18 consecutive seasons and includes a large, homogeneous sample size. It should, however, be acknowledged that a homogeneous data set will decrease the generalisability of the findings to other settings such as female, youth or amateur football.

Several teams have been included or excluded from the study over the course of the 18 seasons of data collection. Even though all of these teams were among the best teams in European football and that the sample thus could be considered fairly homogeneous, it should be acknowledged that injury rates may differ between different teams. Therefore, the results could be influenced by the inclusion and exclusion of teams. However, we performed a sensitivity analysis (data not shown) where we repeated the analyses performed for all outcome variables on a different cohort (in which all teams included in the ECIS were included). The outcomes of these analyses did not differ 
substantially from the outcomes in this study, which we believe further strengthens the findings of the study.

The risk of injury during matches is around seven times higher than it is during training. We would argue that there is no value in discussing trends for overall injury rates (matches combined with training), as such data depend greatly on the ratio of training to matches (exposure). Thus, we argue that injury rates always should be reported separately for match play and training.

Several different injury measures were included in analyses, for example, injury incidence, injury burden and injury absence, to reflect different aspects of the consequences of injuries in professional football. While injury incidence is still the most reported injury rate in epidemiological studies, injury burden, considering both the frequency and severity of injuries, may be a better measure of the full consequences of injuries. ${ }^{27}$ Injury severity may however be difficult to define. In the present study, a time-loss definition of injury was used which means that contact persons were asked to give a date when injured players were considered ready for full participation in all team activities. In practice, return to sport is often a continuum from partial participation to full participation and eventually full performance. It may thus be difficult to give an exact date when players are considered ready for full participation.

It is also possible that players may return to full participation even though they have remaining symptoms that may affect their ability to perform in a competitive environment. These aspects of an injury are not covered using a time-loss definition of injury and are thus not included in our definition of injury burden.

\section{What are the findings?}

- The overall injury rate has decreased in training and matches.

- The ligament injury rate has decreased in training and matches.

- The muscle injury rate has not decreased, neither in training nor in matches.

- The burden of injury has remained stable.

- The reinjury rate has decreased.

- Player absence from training and matches has decreased.

\section{How might it impact on clinical practice in the future?}

- The declining injury incidence that was observed between 2001 and 2019 could be a sign that injury prevention has become increasingly efficient and should encourage medical staff in professional football clubs to continue to implement and monitor preventive programmes in accordance with emerging evidence.

- The fact that injury absence also decreased could be used as a tool to translate this message to other stakeholders in professional football (eg, it should be attractive to managers/ club directors). This may be helpful when health professionals are negotiating to improve medical services for players and to allocate resources to prevent injuries.

\section{Twitter Jan Ekstrand @JanEkstrand and Håkan Bengtsson@HockanB}

Acknowledgements We thank all participating clubs, medical staff and players. Special thanks to Dr Steve McNally, Manchester United, Dr Wart van Zoest, PSV Eindhoven, Dr Nelson Puga, FC Porto, Dr Craig Roberts, AFC Bournemouth, and Professor Dr med Peter Ueblacker, FC Bayern Munich, for field experience contributions.

Contributors JE, AS and HB conceived and designed this part of the ECIS study. HB and JE were involved in data collection over the study period. HB and AS conducted the analyses, which were planned and checked with JE. All authors contributed to interpretation of the findings. JE wrote the first draft of the paper, which was critically revised by AS, HB and RB. The final manuscript was approved by all authors. $J E$ is the study guarantor.

Funding This study was supported by grants from UEFA.

Competing interests None declared.

Patient consent for publication Not required.

Ethics approval The study protocol was reviewed and approved by the UEFA Medical Committee and the UEFA Football Development Division.

Provenance and peer review Not commissioned; externally peer reviewed. Data availability statement No data are available due to confidentiality reasons.

Supplemental material This content has been supplied by the author(s). It has not been vetted by BMJ Publishing Group Limited (BMJ) and may not have been peer-reviewed. Any opinions or recommendations discussed are solely those of the author(s) and are not endorsed by BMJ. BMJ disclaims all liability and responsibility arising from any reliance placed on the content. Where the content includes any translated material, BMJ does not warrant the accuracy and reliability of the translations (including but not limited to local regulations, clinical guidelines, terminology, drug names and drug dosages), and is not responsible for any error and/or omissions arising from translation and adaptation or otherwise.

Open access This is an open access article distributed in accordance with the Creative Commons Attribution Non Commercial (CC BY-NC 4.0) license, which permits others to distribute, remix, adapt, build upon this work non-commercially, and license their derivative works on different terms, provided the original work is properly cited, appropriate credit is given, any changes made indicated, and the use is non-commercial. See: http://creativecommons.org/licenses/by-nc/4.0/.

\section{ORCID iDs}

Jan Ekstrand http://orcid.org/0000-0002-6092-266X

Håkan Bengtsson http://orcid.org/0000-0003-3809-5909

Roald Bahr http://orcid.org/0000-0001-5725-4237

\section{REFERENCES}

1 Dupont G, McCall A. Targeted systems of the body for training. In: Strudwick T, ed. Soccer science chapter 11. Human kinetics, 2016: 221-47.

2 Hägglund M, Waldén M, Magnusson $\mathrm{H}$, et al. Injuries affect team performance negatively in professional football: an 11-year follow-up of the UEFA champions League injury study. Br J Sports Med 2013;47:738-42.

3 Eirale C, Tol JL, Farooq A, et al. Low injury rate strongly correlates with team success in Qatari professional football. Br J Sports Med 2013;47:807-8.

4 Arnason A, Sigurdsson SB, Gudmundsson A, et al. Physical fitness, injuries, and team performance in soccer. Med Sci Sports Exerc 2004;36:278-85.

5 Wv M, Hlobil H. Incidence, Severity, aetiology and prevention of sports injuries. Sports Med 1992;14:82-99.

6 Ekstrand J, Hägglund M, Waldén M. Injury incidence and injury patterns in professional football: the UEFA injury study. Br J Sports Med 2011;45:553-8.

7 Ekstrand J, Hägglund M, Kristenson K, et al. Fewer ligament injuries but no preventive effect on muscle injuries and severe injuries: an 11-year follow-up of the UEFA champions League injury study. Br J Sports Med 2013;47:732-7.

8 Ekstrand J. Preventing injuries in professional football: thinking bigger and working together. Br J Sports Med 2016;50:709-10.

9 Barnes C, Archer D, Hogg B, et al. The evolution of physical and technical performance parameters in the English premier League. Int J Sports Med 2014;35:1095-100.

10 Ekstrand J, Waldén M, Hägglund M. Hamstring injuries have increased by $4 \%$ annually in men's professional football, since 2001: a 13-year longitudinal analysis of the UEFA Elite Club injury study. Br J Sports Med 2016;50:731-7.

11 Waldén $M$, Hägglund $M$, Ekstrand J. Time-trends and circumstances surrounding ankle injuries in men's professional football: an 11-year follow-up of the UEFA champions League injury study. Br J Sports Med 2013;47:748-53.

12 Lundblad M, Waldén M, Magnusson $\mathrm{H}$, et al. The UEFA injury study: 11-year data concerning $346 \mathrm{MCL}$ injuries and time to return to play. Br J Sports Med 2013;47:759-62

13 Waldén $M$, Hägglund M, Magnusson $H$, et al. ACL injuries in men's professional football: a 15-year prospective study on time trends and return-to-play rates reveals only $65 \%$ of players still play at the top level 3 years after $A C L$ rupture. $\mathrm{Br}$ J Sports Med 2016:50:744-50.

14 Werner J, Hägglund M, Ekstrand J, et al. Hip and groin time-loss injuries decreased slightly but injury burden remained constant in men's professional football: the 15year prospective UEFA elite Club injury study. Br J Sports Med 2019;53:539-46.

15 Hägglund M, Waldén M, Bahr R, et al. Methods for epidemiological study of injuries to professional football players: developing the UEFA model. Br J Sports Med 2005;39:340-6. 
16 Fuller CW, Ekstrand J, Junge A, et al. Consensus statement on injury definitions and data collection procedures in studies of football (soccer) injuries. Br J Sports Med 2006;40:193-201.

17 Bahr R, Clarsen B, Derman W. International Olympic Committee consensus statement: methods for recording and reporting of epidemiological data on injury and illness in sports 2020 (including the STROBE extension for sports injury and illness surveillance (STROBE-SIIS). Orthop J Sports Med 2020;8. doi:10.1177/2325967120902908

18 Orchard J. Orchard sports injury classification system (OSICS). Sports Health 1993;11:39-41.

19 Ekstrand J. Keeping your top players on the pitch: the key to football medicine at a professional level. Br J Sports Med 2013;47:723-4.

20 McCall A, Dupont G, Ekstrand J. Injury prevention strategies, coach compliance and player adherence of 33 of the UEFA elite Club injury study teams: a survey of teams' head medical officers. Br J Sports Med 2016;50:725-30.

21 Ekstrand J, Lundqvist D, Lagerbäck L, et al. Is there a correlation between coaches' leadership styles and injuries in elite football teams? A study of 36 elite teams in 17 countries. Br J Sports Med 2018;52:527-31.
22 Ekstrand J, Lundqvist D, Davison $\mathrm{M}$, et al. Communication quality between the medical team and the head coach/manager is associated with injury burden and player availability in elite football clubs. Br J Sports Med 2019;53:304-8.

23 Bahr R, Thorborg K, Ekstrand J. Evidence-Based hamstring injury prevention is not adopted by the majority of champions League or Norwegian premier League football teams: the Nordic hamstring survey. Br J Sports Med 2015;49:1466-71.

24 Arnason A, Tenga A, Engebretsen L, et al. A prospective video-based analysis of injury situations in elite male football: football incident analysis. Am J Sports Med 2004;32:1459-65.

25 Bengtsson $\mathrm{H}$, Ekstrand J, Waldén $\mathrm{M}$, et al. Muscle injury rate in professional football is higher in matches played within 5 days since the previous match: a 14-year prospective study with more than 130000 match observations. Br J Sports Med 2018;52:1116-22.

26 Bittencourt NFN, Meeuwisse WH, Mendonça LD, et al. Complex systems approach for sports injuries: moving from risk factor identification to injury pattern recognitionnarrative review and new concept. Br J Sports Med 2016;50:1309-14.

27 Bahr R, Clarsen B, Ekstrand J. Why we should focus on the burden of injuries and illnesses, not just their incidence. Br J Sports Med 2018;52:1018-21. 